\title{
Infantile Colic - A Challenge to Parenthood
}

Abdulwahab M A Telmesani ${ }^{1}$ and Mohammad N Khan ${ }^{2^{*}}$

${ }^{1}$ Department of Pediatrics, Faculty of Medicine, Umm-Al-Qura University, Makkah, Saudi Arabia

${ }^{2}$ Department of Pediatrics, Faculty of Medicine, Umm-Al-Qura University, Makkah, Saudi Arabia

\begin{abstract}
Infantile colic is a common problem in healthy thriving infants in first few months of life. It is extremely frustrating for parents as it is difficult to treat and may result in abuse and psychosocial consequences. Underlying etiology of colic is poorly understood. It affects 5-25\% of young infants throughout the world. Thorough detailed history and physical examination are mandatory to rule out underlying serious and life threatening conditions. Laboratory tests and radiological investigations are usually not indicated in a thriving healthy child who has normal physical examination. Our aim is to review and assess various management options based on the evidence. Family reassurance and counselling is - themainstay of management. Benign and self-limiting nature of this condition should be emphasized to the parents. Dietary modification is a low-risk option when cow's milk protein allergy is suspected and a short trial of hypoallergenic formula in a bottle fed infant may be considered under supervision. Simethicone, probiotics may be tried in selected cases. Herbal preparation, sucrose solution has limited use in colicky babies due adverse side effects, lack of standardization of dosage, formulation and poor quality of evidence. Dicyclomine, an anticholinergic agent is no longer a therapeutic option due to life threatening serious side effects. Health education and public awareness program regarding how to deal with a crying infant plays a vital role in the management and prevention of any untoward complication.
\end{abstract}

\section{Publication History:}

Received: February 09, 2016

Accepted: May 04, 2016

Published: May 06, 2016

\section{Keywords:}

Infantile colic, Colic, Breastfeeding, Cow milk protein allergy

\section{Introduction}

Infantile colic is one of the major challenges for parents. Also,it isone of the common reasons for parents seeking medical advice for their healthy thriving babies in first three months of life. Persistent inconsolable crying is enough to fray the nerves of even the most tranquil parents. Though it is a benign and self-limiting condition, those affected most by colic are the parents, especially the first time parents [1]. To deal with screaming on a daily basis can drive them to the brink of losing their temper and control of their nerves and resulting into shaking their baby out of frustration causing shaken baby syndrome [2]. In addition, crying spells are also associated with relationship stress, failure of breastfeeding, postpartum depression. It affects 5\%- $25 \%$ of young infants throughout the world [3]. It affects boys and girls alike, although in some report it is found to affect the first born babies more than subsequent ones.

The word colic is derived from the Greek word 'Kolikos'- meaning colon suggesting that it involves some bowel disturbances [3].

The most commonly accepted definition of colic using "rule of three" was described by Wessel et al. [4] as episodes of inconsolable crying in an otherwise healthy infant younger than three months of age that last at least three hours a day and occur at least three days per week over the course of at least three weeks in a month.

More recently Hyman et al. [5] defined colic as infants crying constantly during the evening at about same time each day for at least one week who are otherwise healthy.

The signs which are frequently associated with colic are flushing, abdominal distension, drawing up of legs and arching of the back, tight fists, furrowed brow and high pitched scream [6].

\section{Eitiopathogenesis}

Despite the prevalence of the condition, extensive research, the etiology of infantile colic still remains elusive. Gastrointestinal, psychosocial and neurodevelopmental disorders have been implicated in the underlying cause of colic. Several causative mechanisms have been implicated such as food allergy and hypersensitivity, intestinal hormonal imbalance, immaturity of gut function and dysmotility [6 $-8]$.

It is thought that due to immaturity of nervous system and the bowel, the air is trapped in the colon causing stretching of the bowel, hence the colic. The fact is that most infants outgrow colic by four months of age lends support to a neurodevelopment cause [9].

Gut hormone such as motilin may also play a causative role in the colic. The high level of motilin hormone found in affected babies is thought to cause increase colon peristalsis, leading to colic [10].

More recently, composition of intestinal microflora has been attributed as an independent risk factor for colic. Studies indicate that inadequate amounts of lactobacillus and increased amounts of coliform bacteria like E coli, Kleibsella and anaerobes in the intestine may influence gut motor function and gas production which subsequently contributes to occurrence of colic [10]. Replacing microflora with probiotic like $L$. reuteri was found to have remarkable improvement and less crying episodes [11,12].

Cow milk protein allergy (CMPA) is a common problem affecting $2-3 \%$ of children and is the most prevalent food allergy in infancy. At the same time infantile colic is also a common problem in the first year of life. Several studies have shown that removing cow's milk

*Corresponding Author: Dr. Mohammad N Khan, Department of Pediatrics, Faculty of Medicine, Umm-Al-Qura University, Saudi Arabia, Makkah; E-mail: nasimkhan00@hotmail.com

Citation: Telmesani AMA, Khan MN (2016) Infantile Colic - A Challenge to Parenthood. Int J Community Fam Med 1: 109. doi: http://dx.doi.org/10.15344/ ijcfm/2016/109

Copyright: (C) 2016 Telmesani et al.This is an open-access article distributed under the terms of the Creative Commons Attribution License, which permits unrestricted use, distribution, and reproduction in any medium, provided the original author and source are credited. 
Citation: Telmesani AMA, Khan MN (2016) Infantile Colic - A Challenge to Parenthood. Int J Community Fam Med 1: 109. doi: http://dx.doi.org/10.15344/ ijcfm/2016/109

Page 2 of 3

proteins from a colicky infant's diet can cause a significant reduction in crying episodes. Some of these infants have an IgE mediated reaction commonly known as cow's milk protein allergy, other may exhibit similar symptoms due to non IgE mediated, mixed or cell mediated reaction. Significant percentages of infants with severe colic have cow's milk protein intolerance and in these cases dietary treatment under supervision is low-risk first therapeutic approach [13].The use of hypo-allergenic or extensively hydrolyzed formulas can help in resolving colic. However to make this decision, there should be some evidences suggesting CMPA like atopic eczema, family h/o atopic diseases, bloody stools etc. It has to be said that although some babies do improve on such treatment, the evidence is still not scientifically solid $[14,15]$.

In exclusively breast fed -colicky infants, elimination for cow's milk products from maternal diet is controversial [16]. Some studies have reported a reduction in persistent crying after elimination of cow's milk and other food proteins from mother's diet [17,18 ], but others have reported no beneficial effects [ 19,20].

In a recent study, Moravejetal used skin prick testing (SPT) as a classical allergist's tool for diagnosis of food allergy in exclusively breast- fed colicky infants. Only $2.6 \%$ cases were found to be positive on SPT and elimination of cow's milk products from thematernal diet resulted in complete recovery [21]

Several other factors have been attributed to infantile colic like behavioral issues such as family conflict, maternal anxiety and poor maternal- infant interaction. Parental counselling with behavior modification has been found to have positive effect on colicky babies $[22,23]$

Other concomitant risk factors like maternal smoking, increased maternal age and fist born status may be associated with occurrence of colic.

\section{Clinical Approach}

A careful history and physical examination usually are sufficient to determine if there is an organic cause for crying. A period of calmness followed by specific period of crying in otherwise healthy infant is reassuring. Diagnosis is based on excluding the organic causes (Table 1). Parent and caregiver should be asked to document infant's behavior during spell like time of the day and duration of crying episode. Red flags (Table 2) like history of apnea, cyanotic episodes, fever, respiratory difficulty, failure to thrive; decreased feeding, persistent vomiting, diarrhea and abnormal movement may suggest underlying organic cause. Details of infant's feeding pattern (amount, frequency, type of milk) bowel movement, urination and sleeping patterns should be explored. History should include the family structure and dynamics including the family perception of the problem and social life at home.

Infant is observed while being held on parent's lap .Careful complete physical examination is performed starting from vitals, anterior fontanelles and anthropometric measurements for growth assessment, eye and ear examination, and signs of hair tourniquet of the finger or around penis. A thorough abdominal examination should be performed for any signs of surgical emergencies including examination of testicles for possible torsion. Infant's clothing should be removed to examine for any sign of trauma or abuse like skin bruise, hematoma and fracture. Complete neurological examination is required to rule out any underlying CNS pathology.

\begin{tabular}{|l|l|}
\hline Infections & Meningitis, otitis media, UTI \\
\hline GIT & $\begin{array}{l}\text { Gastroesophageal reflux, cow's milk protein } \\
\text { allergy, bowel intussusception, anal fissure, } \\
\text { constipation, pyloric stenosis, inguinal hernia }\end{array}$ \\
\hline Neurological & Subdural hematoma, hydrocephalus \\
\hline Metabolic & Hypoglycemia \\
\hline Trauma & Accidental trauma, non-accidental injury \\
\hline Musculoskeletal & Fractures, dislocations \\
\hline Rare. & Signs of hair tourniquet of the finger or penis. \\
\hline
\end{tabular}

Table 1: (Differential diagnosis of colic).

\begin{tabular}{|l|l|}
\hline Symptoms & Signs \\
\hline Fever & Apnea, cyanosis \\
\hline Decreased feeding & Pallor \\
\hline Failure to thrive & Respiratory distress, Nasal flaring \\
\hline $\begin{array}{l}\text { Projectile or bilious vomiting, } \\
\text { blood in stools, watery } \\
\text { diarrhea }\end{array}$ & Weight $<$ 5th Percentile \\
\hline $\begin{array}{l}\text { Lethargies } \\
\text { Irregular breathing or } \\
\text { breathing difficulty }\end{array}$ & $\begin{array}{l}\text { Bulging tense fontanels, } \\
\text { Macrocephaly }\end{array}$ \\
\hline Abnormal movements & Bruises, petechial hemorrhages \\
\hline Table 2: (Red flags Signs and Symptoms).
\end{tabular}

Re-examination of the infant sometimes may be necessary especially at the time of the day when infant is not fussy.

Laboratory tests and radiographic examinations usually are not indicated if the child is gaining weight normally and has normal physical examination [24].

If there is history of watery stool, stool may be tested for excess reducing substances to rule out lactose intolerance. Presence of occult blood in stool may suggest cow's milk allergy.

\section{Management Options}

The mainstay of colic management is an acknowledgement by the physician of the difficulties and stress the parents are going through [25]. Single most effective step remains reassurance of parents regarding the benign and self-limiting nature of illness as most of the babies improve by the age of 3-4 months.

As there is lack of consensus on the cause and understanding about the colic, wide spectrum of treatment modalities have been suggested in literature. We will discuss whether these management options are supported by the literature and if there are any novel treatment options.

\section{Dietary intervention}

During initial assessment of a colicky infant, it is crucial to consider the possibility of cow's milk protein allergy if there is history of eczema, family history of atopy, diarrhea etc. Several studies have demonstrated that completely hydrolyzed formulas significantly improved the clinical symptoms of infantile colic in terms of duration and frequency of crying episodes [26,27]. The improvement was noted as early as seven days after the introduction of hydrolyzed formula. 
In onecontrolled trial which was done comparing partially hydrolyzed formula with soy based formula, there was reduction in colicky symptoms after fourteen days of introduction of partially hydrolyzed formula [27].

While there are few studies recommending the use of partially hydrolyzed formula others do not advocate it in cases of infantile colic as partially hydrolyzed formula is not hypoallergenic and therefore it will not be helpful in cases where colicky symptoms are secondary to protein allergy [27].

There was no significant difference in colicky symptoms when high fibre formula was compared with standard formula [26, 27].

Due to concern about the level of phytoestrogen in soy based formula and due to possibility of allergy, it is not recommended in babies with infantile colic [28].

While hypoallergenic maternal diet with exclusion of milk and milk products in breastfeeding mothers may occasionally benefit in decreasing the crying episodes in colic infants,several other studies have not shown any beneficial effects[26 -28].

\section{Pharmacological treatment}

Pharmacological treatment is aimed at reducing the increased peristaltic activity of gut. Anticholinergics such as dicyclomine hydrochloride and dicycloverine have been found to be effective in reducing crying episodes compared with placebo. However, evidence does not support the use of these drugs because of reported seriousside effects like apnea, seizure in infants less than 6months of age [2].

Simethicone facilitates gas bubbles within the gut to coalesce and reduces gas production. But other randomized controlled trials regarding use of simethicone found no difference in reducing crying episode as compared to placebo $[26,2]$.

\section{Alternative therapies}

In the absence of safe and effective pharmacological intervention, alternatetherapy has taken more popular role in the management of infantile colic. In numerous clinical trials several alternative medicines and remedies have been experimented in the treatment of colicky infants.

Probiotics: Use of probiotics in infantile colic is based on assumption that aberrant intestinal microflora could cause gut dysfunction and gas production contributing to colicky symptoms. There is enormous interest in medical research about use of probiotic bacterial strains in reducing pathogenic gastrointestinal microorganism and its beneficial effects. The beneficial effect could be attributed to improvement in gut function and motility. Some studies have shown that administration of Lactobacillus reuteriATC 55730 and its daughter strain Lactobacillus reuteri DSM 17938 to breast fed infants significantly improved the symptoms of infantile colic compared with seminthicone or placebo $[12,29]$.In another randomized controlled trial, Indrio et al. [30] showed the efficacy of $L$. reuteriin preventing infantile colic in breast fed infants. However, more independent large studies are required especially in formula fed infants in diverse ethnic set up to recommend its use.

Calming techniques: Some parents have used various calming techniques in reducing crying episode in colicky infants. These are5Ss
- $\quad$ Side or stomach position -holding a baby on the back is the only safe position for sleep but it is the worst position for calming a crying baby

- Swaddling-Swaddling is an age-old practice of wrapping infants in blankets or similar cloths so that movement of the limbs is tightly restricted. However there is a known associated risk of hip dysplasia, overheating, and sudden infant death syndrome. The current evidence does not support the use of swaddling in the management of infantile colic [31].

- Shhh sound - making a strong shush sound near the baby's ear [32]

- $\quad$ Swinging the baby with tiny jiggly movements [33]

- Sucking - letting the baby suckle on the breast or parents clean finger or pacifier

Massage: Massage and vibrating machine have been found to have a positive effect by aborting crying episode. Similarly crying usually stops if the baby is taken on a ride in a car. These techniques need further studies and confirmation.

Herbal supplements: Several studies have shown the beneficial effects of herbal agents like chamomile (Matricariae recutia), fennel extract (Foeniculum vulgare) and lemon balm (Melissa officinalis)in reduction of symptoms in colicky infants, however parents should be warned about overuse and associated risk like vomiting, sleepiness, constipation and loss of appetite $[34,35]$.

Sucrose solution: Two studies have compared sucrose solution with placebo and found to be beneficial in relieving symptoms of colic but there are concerns about its potential nutritional effects $[35,36]$.

Spinal manipulation: Spinal manipulation / chiropractic treatment has been traditionally used in colicky infant by physiotherapist, osteopaths. It may offer short term benefit in reduction of duration of crying, but long term benefits are not demonstrated.Due to paucity of good quality RCT regarding its use in colicky infants, physician should be cautious in recommending it $[37,38]$.

Acupuncture: There are conflicting reports about the use of acupuncture in infants with colic. While some studies have shown reduction in frequency and duration of crying episodes in infantile colic, others noted no major effects on symptoms [39 - 41]. Further studies are needed to justify its use in infantile colic.

Behavior modification: Several behavioral interventions like supplemental carrying, car ride simulator, intensive parents training, decreasing infant stimulation has been tried to provide reassurance to the parents and offer an alternative method in the treatment of infantile colic $[42,43]$.There is not sufficient data to recommend these measures as an effective intervention.

It's important to remember that what works for one baby, may not necessarily work for other. Measures like importance of feeding a hungry baby, changing wet diapers; soothing music accompanied with parental attention (including eye contact, talking, touching, rocking, playing) may be effective in some babies and is never harmful.

\section{Public Educations and Awareness Program}

Many of the hospitals use a program based on the one developed in the the United States that significantly reduces the risk of shaken 
Citation: Telmesani AMA, Khan MN (2016) Infantile Colic - A Challenge to Parenthood. Int J Community Fam Med 1: 109. doi: http://dx.doi.org/10.15344/ ijcfm/2016/109

Page 3 of 3

baby syndrome in colicky infants. The program includes a pamphlet, handed out to parents of infants in the emergency room, among others, that tells parents that infant's crying is normal and usually peaks at about six to eight weeks and then begins to decline. It gives advice about soothing babies and about planning for how to deal with frustration.

\section{When you're frustrated, your plan could be}

- Put your baby down in a safe place (like a crib) and walk away for a few minutes.

- $\quad$ Check on your baby every few minutes but don't pick him up until you feel calmer.

- Do something to make yourself feel better during this time (lie down, listen to music, or have a snack).

- "Call someone to help," the pamphlet suggests.

\section{Conclusion}

Infantile colic is often a stressful problem for parents and a challenge to parenthood. The proper approach for crying baby is to have a detailed history and complete physical examination to exclude serious and life threating conditions. Family reassurance and counselling is the mainstay of management.Benign and self-limiting nature of this condition should be emphasized to the parents. Parents should be encouraged to try behavior modification which would help to destress them. Dietary modification under supervision is a goodlowrisk option in bottle-fed colicky infants when cow's milk protein allergy is suspected. Hypoallergenic maternal diet with exclusion of milk and milk products in breastfeeding mothers may be helpful in some cases. Currently there are no effective and safe pharmacological management options available. Future research is needed for evidence based treatment protocols.

\section{Competing Interests}

The authors declare that they have no competing interests.

\section{References}

1. Roberts DM, Ostapchuk M, O'Brien JG (2004) Infantile colic. Am Fam Physician 70: 735-740.

2. Catherine NL, Ko JJ, Barr RG (2008) Getting the word out: advice on crying and colic in popular parenting magazines. J Dev Behav Pediatr 29: 508511

3. Clifford TJ, Campbell MK, Speechley KN, Gorodzinsky F (2002) Sequelae of infant colic: evidence of transient infant distress and absence of lasting effects on maternal mental health. Arch Pediatr Adolesc Med 156: 11831188.

4. WESSEL MA, COBB JC, JACKSON EB, HARRIS GS Jr, DETWILER AC (1954) Paroxysmal fussing in infancy, sometimes called colic. Pediatrics 14: $421-435$.

5. Hyman PE, Milla PJ, Benninga MA, Davidson GP, Fleisher DF, et al (2006) Childhood functional gastrointestinal disorders: neonate/toddler Gastroenterology 130: 1519-1526.

6. Lucassen PL, Assendelft WJ, Gubbels JW, van Eijk JT, van Geldrop WJ, et al. (1998) Effectiveness of treatments for infantile colic: systematic review. BMJ 316: 1563-1569.

7. Miller AR, Barr RG (1991) Infantile colic. Is it a gut issue? Pediatr Clin North Am 38: 1407-1423.

8. Treem WR (1994) Infant colic. A pediatric gastroenterologist's perspective Pediatr Clin North Am 41: 1121-1138.

9. Barr RG (1998) Colic and crying syndromes in infants. Pediatrics 102 $1282-1286$.
10. Gupta SK (2002) Is colic a gastrointestinal disorder? Curr Opin Pediatr 14: 588-592.

11. Savino F, Cordisco L, Tarasco V, Calabrese R, Palumeri E, et al. (2009) Molecular identification of coliform bacteria from colicky breastfed infants. Acta Paediatr 98: 1582-1588.

12. Savino F, Cordisco L, Tarasco V, Palumeri E, Calabrese R, et al. (2010) Lactobacillus: Lactobacillus reuteri DSM 17938 in Infantile Colic: A Randomized, Double-Blind, Placebo-Controlled Trial: Pediatrics 126: e526-e533.

13. Iacono G, Carroccio A, Montalto G, Cavataio F, Bragion E, et al. (1991) Severe infantile colic and food intolerance: a long-term prospective study. J Pediatr Gastroenterol Nutr 12: 332-335.

14. Leung AK, Lemay JF (2004) Infantile colic: a review. J R Soc Promot Health 124: 162-166.

15. Lucas A, St James-Roberts I (1998) Crying, fussing and colic behaviour in breast- and bottle-fed infants. Early Hum Dev 53: 9-18.

16. Hill DJ, Hosking CS (2000) Infantile colic and food hypersensitivity. J Pediatr Gastroenterol Nutr 30 Suppl: S67-76.

17. Jakobsson I, Lindberg T (1983) Cow's milk proteins cause infantile colic in breast-fed infants: a double-blind crossover study. Pediatrics 71: 268-271.

18. Hill DJ, Hudson IL, Sheffield LJ, Shelton MJ, Menahem S, et al. (1995) A low allergen diet is a significant intervention in infantile colic: results of a community-based study. J Allergy Clin Immunol 96: 886-892.

19. Evans RW, Fergusson DM, Allardyce RA, Taylor B (1981) Maternal diet and infantile colic in breast-fed infants. Lancet 1: 1340-1342.

20. Garrison MM, Christakis DA (2000) A systematic review of treatments for infant colic. Pediatrics 106: 184-190.

21. Moravej H, Imanieh MH, Kashef S, Handjani F, Eghterdari F (2010) Predictive value of the cow's milk skin prick test in infantile colic. Ann Saudi Med 30: 468-470.

22. Balon AJ (1997) Management of infantile colic. Am Fam Physician 55: 235242, 245-246.

23. Keefe MR, Kajrlsen KA, Lobo ML, Kotzer AM, Dudley WN (2006) Reducing parenting stress in families with irritable infants. Nurs Res 55: 198-205.

24. Weissbluth M (1999) Colic. In: Burg FD, Gellis SS, Kagan BM. Gellis\& Kagan's Current pediatric therapy. 16th ed. Philadelphia: Saunders 674678.

25. Levitzky S, Cooper R (2000) Infant colic syndrome--maternal fantasies of aggression and infanticide. Clin Pediatr (Phila) 39: 395-400.

26. Hall B, Chesters J, Robinson A (2012) Infantile colic: a systematic review of medical and conventional therapies. J Paediatr Child Health 48: 128-137.

27. lacovou M, Ralston RA, Muir J, Walker KZ, Truby H (2012) Dietary management of infantile colic: a systematic review. Matern Child Health J 16: 1319-1331.

28. Critch J (2011) Infantile colic: Is there a role for dietary interventions? Paediatr Child Health 16: 47-49.

29. SavinoF,Cerrato $S$ (2012) Advances in infantile colic and the use of probiotics. Funct Food Rev 4:152-157

30. Indrio F, Di Mauro A, Riezzo G, Civardi E, Intini C, et al. (2014) Prophylactic use of a probiotic in the prevention of colic, regurgitation, and functional constipation: a randomized clinical trial. JAMA Pediatr 168: 228-233.

31. Gerard CM, Harris KA, Thach BT (2002) Physiologic studies on swaddling: an ancient child care practice, which may promote the supine position for infant sleep. J Pediatr 141: 398-403.

32. Brackbill Y, Adams G, Crowell DH, Gray ML (1966) Arousal level in neonates and preschool children under continuous auditory stimulation. $J$ Exp Child Psychol 4: 178-188.

33. Brackbill $Y$ (1971) Cumulative effects of continuous stimulation on arousal level in infants. Child Dev 42: 17-26.

34. Weizman Z, Alkrinawi S, Goldfarb D, Bitran C (1993) Efficacy of herbal tea preparation in infantile colic. J Pediatr 122: 650-652. 
Citation: Telmesani AMA, Khan MN (2016) Infantile Colic - A Challenge to Parenthood. Int J Community Fam Med 1: 109. doi: http://dx.doi.org/10.15344/ ijcfm/2016/109

35. Perry R, Hunt K, Ernst E (2011) Nutritional supplements and other complementary medicines for infantile colic: a systematic review. Pediatrics 127: 720-733.

36. Savino F, Tarasco V (2010) New treatments for infant colic. Curr Opin Pediatr 22: 791-797.

37. Olafsdottir E, Forshei S, Fluge G, Markestad T (2001) Randomised controlled trial of infantile colic treated with chiropractic spinal manipulation. Arch Dis Child 84: 138-141.

38. Wiberg JM, Nordsteen J, Nilsson N (1999) The short-term effect of spinal manipulation in the treatment of infantile colic: a randomized controlled clinical trial with a blinded observer. J Manipulative Physiol Ther 22: 517522

39. Landgren K, Kvorning N, Hallström I (2010) Acupuncture reduces crying in infants with infantile colic: a randomised, controlled, blind clinical study. Acupunct Med 28: 174-179.

40. Reinthal M, Andersson S, Gustafsson M, Plos K, Lund I, Lundeberg T, et al. Effects of minimal acupuncture in children with infantile colic-a prospective, quasi-randomised single blind controlled trial Acupunct Med 2008;26:171-82.

41. Landgren K, Kvorning N, Hallström I (2011) Feeding, stooling and sleeping patterns in infants with colic--a randomized controlled trial of minimal acupuncture. BMC Complement Altern Med 11: 93

42. Barr RG, McMullan SJ, Spiess H, Leduc DG, Yaremko J, et al. (1991) Carrying as colic "therapy": a randomized controlled trial. Pediatrics 87 $623-630$

43. McKenzie S (1991) Troublesome crying in infants: effect of advice to reduce stimulation. Arch Dis Child 66: 1416-1420. 